\title{
Serum Carcinoembryonic Antigen for Recurrence in Colorectal Cancer Patients
}

\author{
Young Jin Kim \\ Clinic of Colorectal Cancer, Department of Surgery, Chonnam National University Medical School, Gwangju, Korea
}

See Article on Page 156-160

Carcinoembryonic antigen (CEA) is secreted by most colorectal cancers, and the CEA level reflects the burden of the tumor present. An elevated preoperative CEA level is a poor prognostic factor for colorectal cancer [1], and the prognosis is better in those patients whose elevated preoperative CEA level is normalized postoperatively.

Although an elevated postoperative CEA level is not specific for recurrent colorectal cancer, a rising CEA level on serial examinations and a new solid mass on imaging studies are diagnostic of metastatic disease. The role of CEA in patients following definitive management of colorectal cancer has been evaluated, and the American Society of Clinical Oncology recommended that postoperative serum CEA tests be performed every 3 months in patients with stage II or III disease for up to 3 years after diagnosis [2].

Postoperative serum CEA surveillance was more useful when patients had high preoperative serum CEA levels [3]. When the elevated postoperative serum CEA in stage III (71.9\%) was higher than that in stage II colorectal cancer patients (41.8\%), the incidence of recurrence was low [4]. The 18F-fluorodeoxyglucose positron emission tomography/computed tomography (CT) has an additional role in patients with isolated elevated CEA levels or positive contrast enhanced CT findings without accompanying CEA elevation [5]. Although the CEA is not an ideal tumor marker, the preoperative and the postoperative CEA levels are useful and cost effective for determining a prognosis and for predicting recurrence in colorectal cancer patients.

Correspondence to: Young Jin Kim, M. D.

Department of Surgery, Chonnam National University Hwasun Hospital, Chonnam National University Medical School, 322 Seoyang-ro, Hwasun 519-763, Korea

Tel: +82-61-379-7642, Fax: +82-61-379-7661

E-mail: kimyjin@jnu.ac.kr

(c) 2013 The Korean Society of Coloproctology

This is an open-access article distributed under the terms of the Creative Commons Attribution NonCommercial License (http://creativecommons.org/licenses/by-nc/3.0) which permits unrestricted noncommercial use, distribution, and reproduction in any medium, provided the original work is properly cited.

\section{REFERENCES}

1. Harrison LE, Guillem JG, Paty P, Cohen AM. Preoperative carcinoembryonic antigen predicts outcomes in node-negative colon cancer patients: a multivariate analysis of 572 patients. J Am Coll Surg 1997;185:55-9.

2. Clinical practice guidelines for the use of tumor markers in breast and colorectal cancer. Adopted on May 17, 1996 by the American Society of Clinical Oncology. J Clin Oncol 1996;14:2843-77.

3. Park IJ, Choi GS, Lim KH, Kang BM, Jun SH. Serum carcinoembryonic antigen monitoring after curative resection for colorectal cancer: clinical significance of the preoperative level. Ann Surg Oncol 2009;16:3087-93.

4. Kim HS, Lee MR. Diagnostic accuracy of elevated serum carcinoembryonic antigen for recurrence in postoperative stage II colorectal cancer patients: comparison with stage III. Ann Coloproctol 2013;29:156-60.

5. Ozkan E, Soydal C, Araz M, Aras G. Serum carcinoembryonic antigen measurement, abdominal contrast-enhanced computed tomography, and fluorine-18 fluorodeoxyglucose positron emission tomography/computed tomography in the detection of colorectal cancer recurrence: a correlative study. Nucl Med Commun 2012; 33:990-4. 